Received: 07.10 .2018

Revised: 05.11.2018

Accepted: 07.12.2018

DOI: $10.17804 / 2410-9908.2018 .6 .008-017$

\title{
ON THE APPLICABILITY OF ELECTROMAGNETIC TESTING METHODS TO DETECTING DISCONTINUITIES IN STEEL STRUCTURES INTENDED FOR OPERATION IN AGGRESSIVE MEDIA UNDER EXTREME LOADS
}

\author{
S. M. Zadvorkin ${ }^{1, \text { a) }}$, V. P. Shveikin ${ }^{1, \text { b)* }}$, S. T. Kalashnikov ${ }^{2}$, and N. P. Antenorova ${ }^{1, c)}$ \\ ${ }^{1}$ Institute of Engineering Science, Ural Branch of the Russian Academy of Sciences, \\ 620049, 34 Komsomolskaya st., Ekaterinburg, Russian Federation \\ ${ }^{2}$ South-Ural Federal Scientific Center UB RAS \\ b) (iD \\ https://orcid.org/0000-0002-7918-8207; zadvorkin@imach.uran.ru ; \\ https://orcid.org/0000-0002-9316-1369 ; ه shveikin60@mail.ru ; \\ iD https://orcid.org/0000-0002-8053-2490 \\ *Corresponding author. E-mail: shveikin60@mail.ru \\ Address for correspondence: ul. Komsomolskaya, 34, Ekaterinburg, 620049, Russian Federation \\ Tel.: +7 (343) 3742594
}

Model specimens in the form of rings made of high-strength corrosion resistance steel (09Kh16N4B-Sh) are tested for corrosion under voltage in order to produce artificial defects in the form of corrosion pits and surface cracks. The specimens served to test the effectiveness of the magnetic particle, ferroprobe and eddy current testing techniques for detecting discontinuities in high-duty products made of the steel under study. The study has shown that magnetic particle testing by the applied field method, the ferroprobe and eddy current techniques offer a reliable detection of defects in the form of regions of pit corrosion and surface cracks on products made of the 09Kh16N4B steel. All the three techniques enable one to locate defects and estimate their sizes.

Keywords: strength, mechanical-thermal treatment, useful life, nondestructive testing, flaw detection, magnetic particle testing, ferroprobe testing, eddy current testing.

\section{Acknowledgment}

The equipment of the Plastometriya collective use center affiliated to the IES UB RAS was used in the research.

The work was supported by the Comprehensive Program of UB RAS (Basic Research Targeted at Hi-Tech Scientific and Industrial Enterprises), project No.18-11-1-11 Development of Models of the Degradation of the Functional Properties of Materials for Rocket Equipment Subjected to Long-Term Storage and Operation.

\section{References}

1. Gorkunov E.S. Magnitoporoshkovaya defektoskopiya i magnitnaya strukturoskopiya. Metodicheskie rekomendatsii [Magnaflux Inspection and Magnetic Structuroscopy: Methodological Guidelines]. Ekaterinburg, UrO RAN Publ., 1999, 140 p. (In Russian).

2. Shelihov G. S. Magnetic particle method - a factor in increasing the reliability of complex technical objects. Kontrol'. Diagnostika, 2014, no. 3, pp. 24-29. DOI: 10.14489/td.2014.03. pp.024-029. (In Russian).

3. Gorkunov E.S., Bashkov Yu.F., Durnitsky V.N., Tabachnik V.P. Magnetizer, RF Patent 33653 (In Russian). 
4. Bakunov A.S., Gorkunov E.S., Shcherbinin V.E. Magnitnyi control [Magnetic Testing]. Moscow, Izd. Dom Spektr Publ., 2011, 192 p. (In Russian).

5. Shcherbinin V.E., Kostin V.N., Smorodinskii Ya.G., Nichipuruk A.P., Rinkevich A.B., Shleenkov A.S., Patramanskii B.V., and Loskutov V.E. On necessary measures for ensuring safe operation of pipeline transport using nondestructive testing methods. Russ. J. Nondestr. Test., 2011, no. 12, pp. 842-851.

6. Reutov Yu.Ya., Shcherbinin V.E., Volkov A.V. Possibilities for the selection of magnetic field transducers for nondestructive testing. Russian Journal of Nondestructive Testing, 2014, vol. 50, iss 12, pp. 760-768. DOI: 10.1134/S1061830914120080. 
Подана в журнал: 07.10.2018

УДК 620.179.1

DOI: $10.17804 / 2410-9908.2018 .6 .008-017$

\title{
О ВОЗМОЖНОСТИ ПРИМЕНЕНИЯ ЭЛЕКТРОМАГНИТНЫХ МЕТОДОВ КОНТРОЛЯ ДЛЯ ОБНАРУЖЕНИЯ ДЕФЕКТОВ СПЛОШНОСТИ СТАЛЬНЫХ КОНСТРУКЦИЙ, ПРЕДНАЗНАЧЕННЫХ ДЛЯ ЭКСПЛУАТАЦИИ В АГРЕССИВНЫХ СРЕДАХ ПРИ ЭКСТРЕМАЛЬНЫХ НАГРУЗКАХ
}

\author{
С. М. Задворкин ${ }^{\text {a) }}$, В. П. Швейкин ${ }^{\text {б) }}$, С. Т. Калашников ${ }^{2}$, Н. П. Антенорова ${ }^{\text {в) }}$
}

${ }^{1}$ Институт машиноведения Уральского отделения Российской академии наук, ул. Комсомольская, 34, Екатеринбург, Российская Федераиия

${ }^{2}$ Южно-Уральский федеральный научный ичентр УрО РАН

a) ID https://orcid.org/0000-0002-7918-8207; zadvorkin@imach.uran.ru ;

б) iD https://orcid.org/0000-0002-9316-1369; ; shveikin60@ mail.ru ;

в) (iD https://orcid.org/0000-0002-8053-2490

*Ответственный автор. Электронная почта: shveikin60@mail.ru Адрес для переписки: ул. Комсомольская, 34, 620049, Екатеринбург, Российская Федерация Tel.: +7 (343) 374-25-94

Модельные образцы в виде колец из высокопрочной коррозионностойкой стали 09Х16Н4Б-Ш подвергались испытаниям на коррозию под напряжением с целью получения искусственных дефектов в виде коррозионных язв и поверхностных трещин.

На указанных образцах была проверена эффективность магнитопорошкового, феррозондового и вихретокового методов контроля обнаружения дефектов сплошности в изделиях ответственного назначения из исследованной стали. Проведенные исследования показали, что магнитопорошковая дефектоскопия способом приложенного поля, феррозондовый и вихретоковый методы позволяют надежно выявлять дефекты в виде очагов язвенной коррозии и поверхностных трещин на изделиях из стали 09Х16Н4Б. Все три метода позволяют определять местоположение дефектов и оценивать их размеры.

Ключевые слова: прочность, механико-теримическая обработка, нормативный срок службы, неразрушающий контроль, дефектоскопия, магнитопорошковый контроль, феррозондовый контроль, вихретоковый контроль.

\section{1. Введение}

При изготовлении силовых элементов конструкций ответственных и потенциально опасных объектов техники применяются высокопрочные металлические материалы, к которым предъявляются повышенные требования по сохранности физико-механических характеристик, а также отсутствию дефектов сплошности, которые могут возникнуть в конструкции вследствие, например, коррозионных повреждений в течение гарантийных и увеличенных сроков эксплуатации. В связи с этим проблема раннего обнаружения коррозионных дефектов на силовых элементах конструкций ответственного назначения является одной из наиболее актуальных.

Цель настоящей работы - определение возможностей неразрушающих магнитных и электромагнитных методов контроля дефектов сплошности стальных изделий ответственного назначения, предназначенных для эксплуатации в экстремальных условиях. 


\section{2. Материал и методы исследования}

Объектом исследования служила высокопрочная мартенситная сталь марки 09Х16Н4Б-Ш, предназначенная для изготовления деталей ответственного назначения. Предел текучести - около 900 МПа, временное сопротивление - около 1200 МПа. Поскольку эта сталь имеет значительную намагниченность насыщения (примерно 13 MA/м), в качестве основных методов неразрушающего контроля дефектов в образцах были выбраны магнитный порошковый, магнитный феррозондовый и вихретоковый методы. Химический состав двух образцов исследованной стали 09Х16Н4Б-Ш приведен в табл. 1.

Микроструктура исследованной стали представляет мелкоигольчатый мартенсит и остаточный аустенит (рис. 1).

С целью создания дефектов сплошности путем проведения испытаний на коррозию под напряжением изготавливались образцы в виде колец размерами $\varnothing 140 \times 14 \times 14$ мм путем вырезания из реальных изделий. Внешний вид образцов представлен на рис. 2.

На всех кольцах были сделаны радиальные разрезы в виде сектора с центральным углом $5^{\circ}$. В эти разрезы были запрессованы стальные клинья, обеспечивающие на внутренней поверхности этих модельных образцов растягивающих напряжений, близких по величине к пределу текучести материала. Внешний вид образца во время испытания представлен на рис. 3.

Таблица 1 - Химический состав стали 09Х16Н4Б-Ш

\begin{tabular}{|c|c|c|c|c|c|c|c|c|}
\hline \multirow{2}{*}{$№$} & \multicolumn{7}{|c|}{ Содержание элементов, \% } \\
\cline { 2 - 9 } & $\mathrm{C}$ & $\mathrm{Si}$ & $\mathrm{Mn}$ & $\mathrm{P}$ & $\mathrm{S}$ & $\mathrm{Cr}$ & $\mathrm{Ni}$ & Cо \\
\hline 1 & 0,104 & 0,466 & 0,325 & 0,021 & 0,0042 & 15,95 & 4,22 & 0,019 \\
\hline 2 & 0,117 & 0,479 & 0,307 & 0,018 & 0,0051 & 15,53 & 3,81 & 0,026 \\
\hline \multirow{2}{*}{$№$} & \multicolumn{7}{|c|}{ Содержание элементов, \% } \\
\cline { 2 - 9 } & $\mathrm{Ti}$ & $\mathrm{Nb}$ & $\mathrm{V}$ & $\mathrm{W}$ & $\mathrm{As}$ & $\mathrm{Bi}$ & $\mathrm{Cu}$ & $\mathrm{Fe}$ \\
\hline 1 & $<0,001$ & 0,106 & 0,023 & 0,019 & 0,0098 & $<0,0020$ & 0,119 & 78,5 \\
\hline 2 & 0,0027 & 0,107 & 0,029 & 0,025 & 0,016 & $<0,0020$ & 0,109 & 79,3 \\
\hline
\end{tabular}

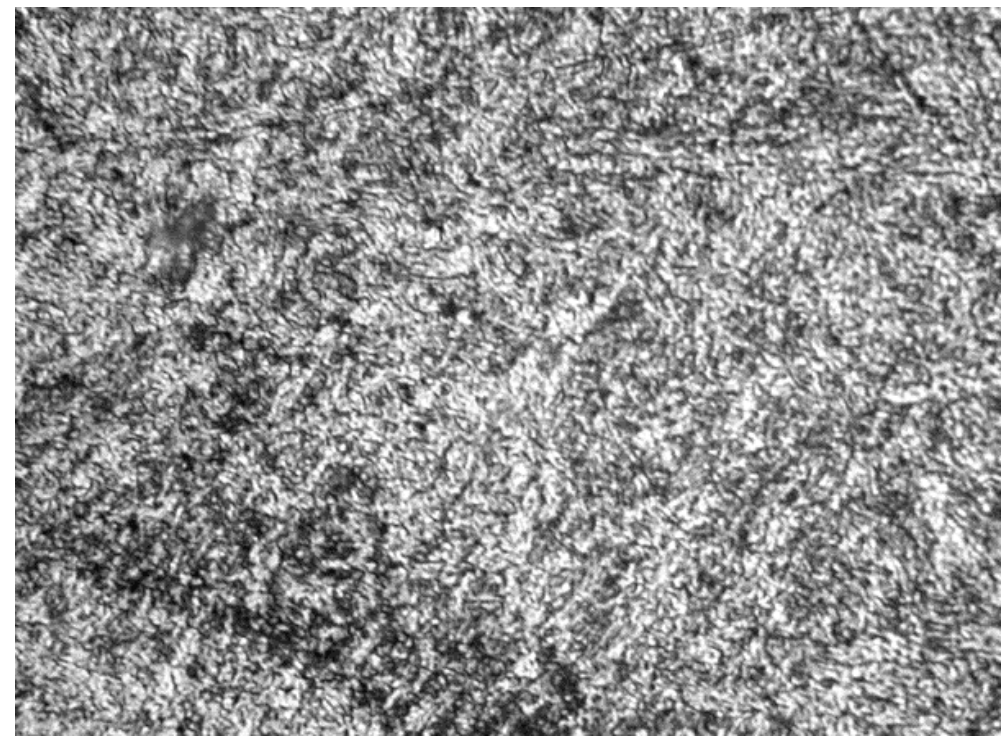

Рис. 1. Микроструктура стали 09Х16Н4Б-Ш, ×1000 


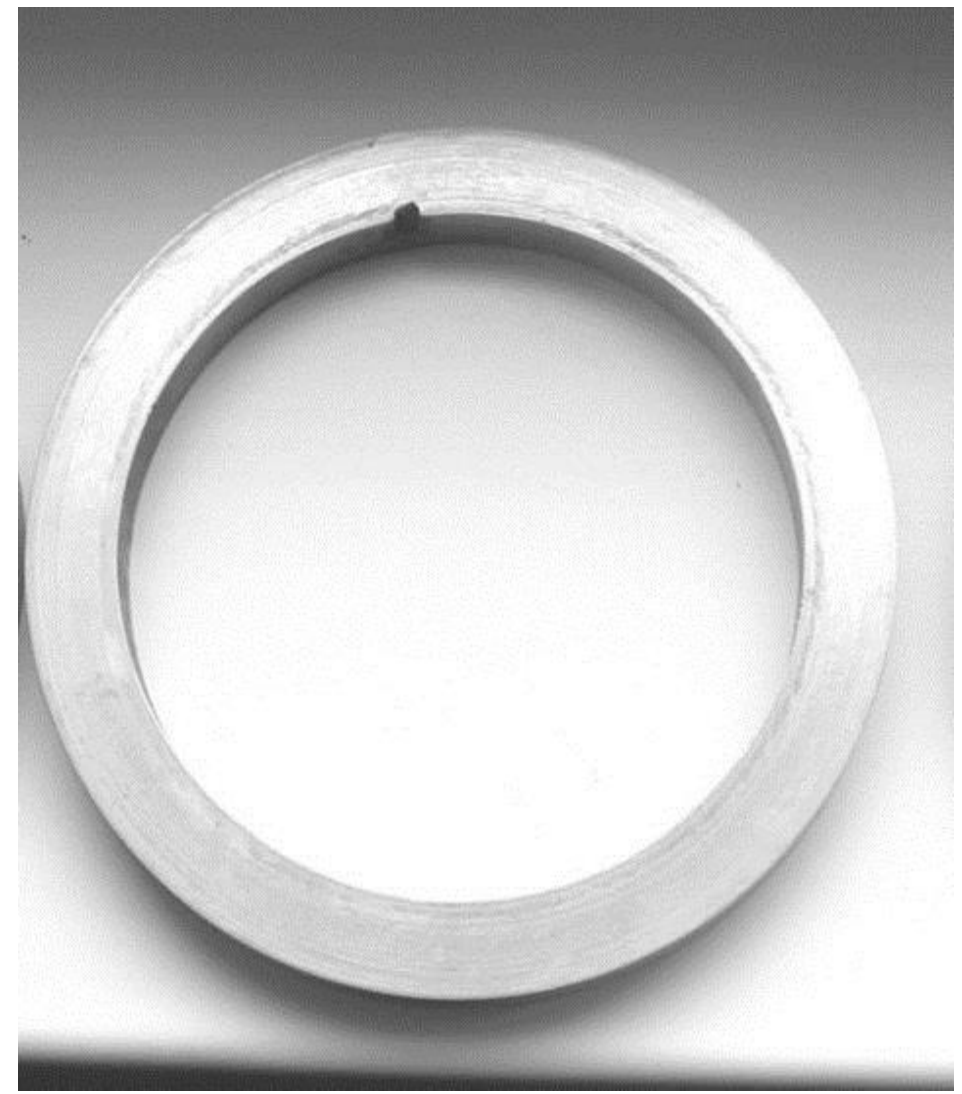

Рис. 2. Внешний вид образцов

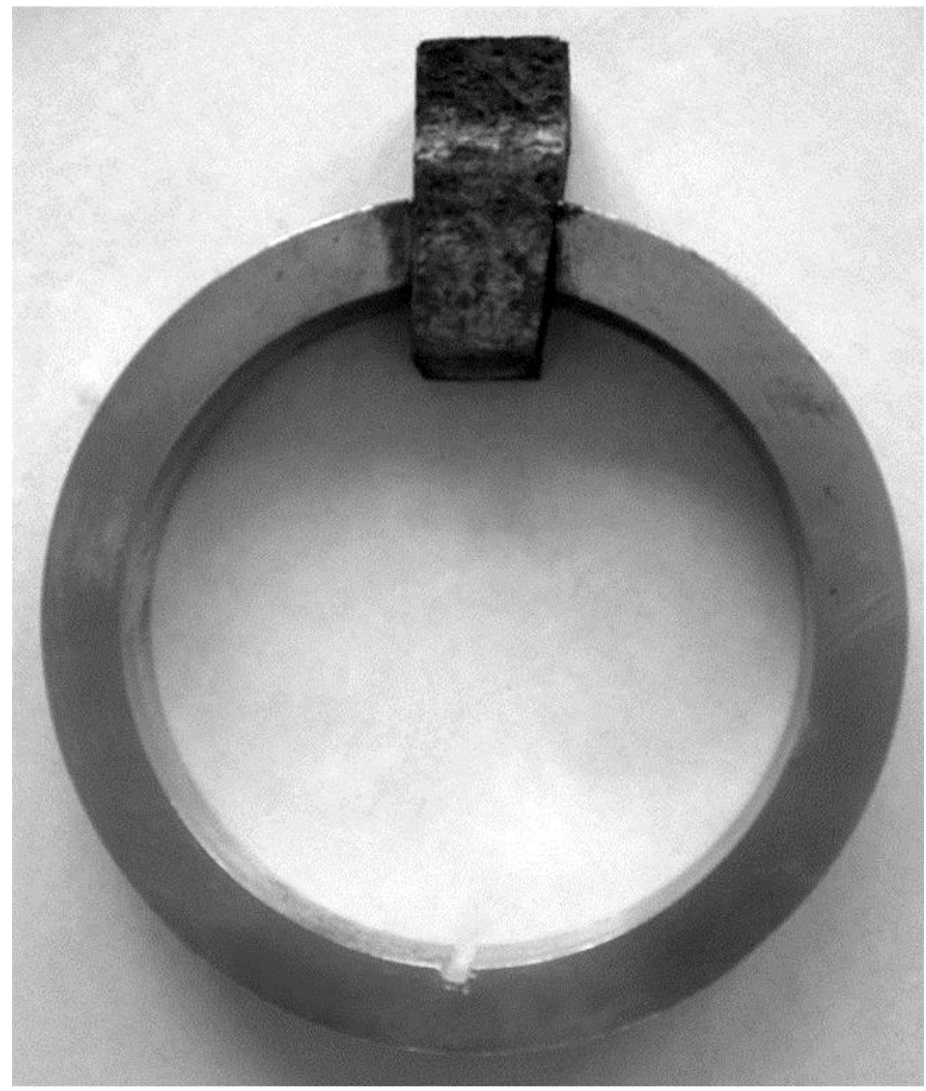

Рис. 3. Внешний вид кольцевого образца, подвергаемого испытанию на коррозию под напряжением

On the applicability of electromagnetic testing methods to detecting discontinuities in steel structures intended for operation in aggressive media under extreme loads / S. M. Zadvorkin, V. P. Shveikin, S. T. Kalashnikov, N. P. Antenorova // Diagnostics, Resource and Mechanics of materials and structures. - 2018. - Iss. 6. - P. 8-17. - DOI: 10.17804/2410-9908.2018.6.008-017. 
Для испытания на коррозию под напряжением модельные образцы были погружены в 25 \%-ный раствор морской соли. После двух суток вылеживания в растворе вблизи наружной цилиндрической поверхности модельного образца появляется дефект в виде участка язвенной коррозии, который увеличивается по мере дальнейшего испытания. Его внешний вид представлен на рис. 4. Для выявления причин коррозии был проведен микроанализ на сканирующем микроскопе «TESCAN». Оказалось, что в зоне язвенной коррозии наблюдается локальное изменение химического состава (большое содержание кислорода, серы, натрия, калия, кальция, магния) по сравнению с расположенным рядом непораженным участком, химический состав которого близок к результатам, приведены в табл. 1.

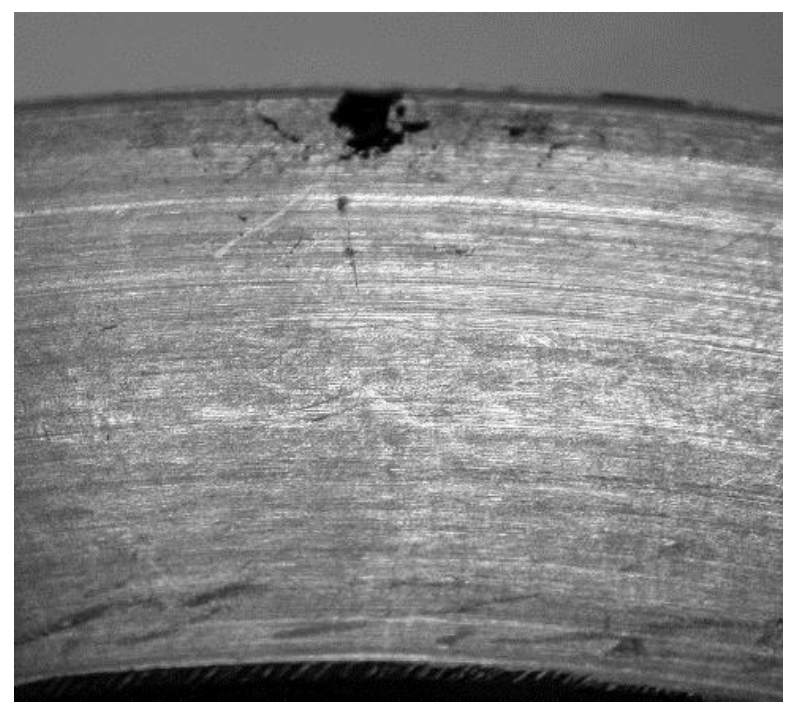

Рис. 4. Язвенная коррозия кольцевого образца из стали 09Х16Н4Б-Ш после вылеживания в $25 \%$-ном растворе морской соли при комнатной температуре

На внутренней цилиндрической поверхности образцов на 2-3 сутки вылеживания в растворе появились множественные вертикальные дефекты типа трещин (рис. 5), которые при дальнейшем вылеживании не имели развития.

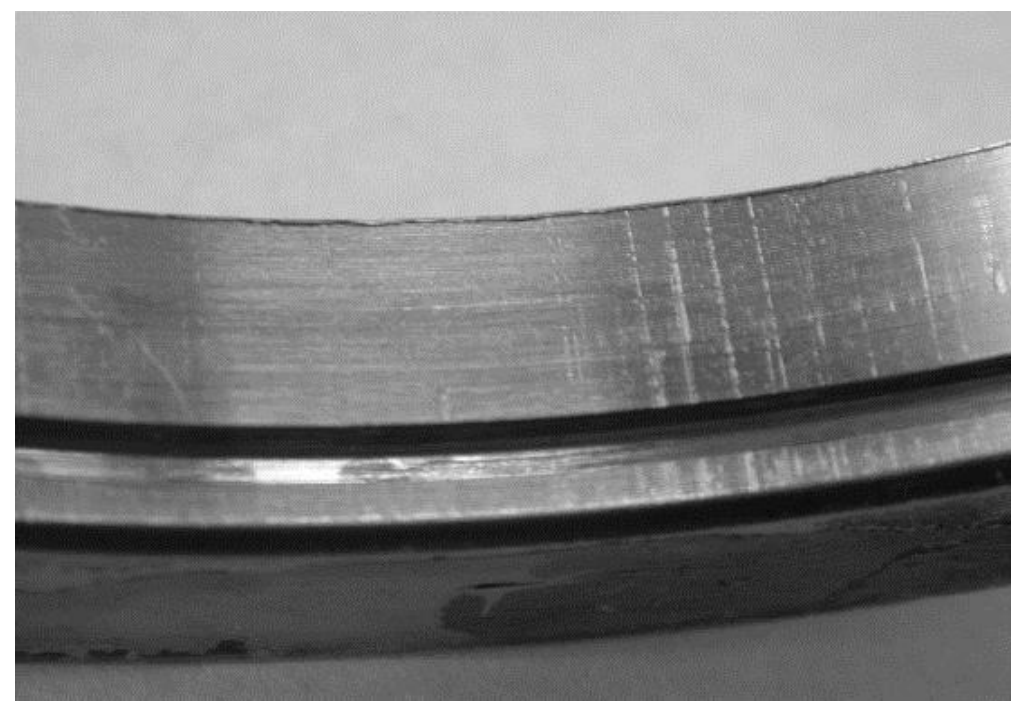

Рис. 5. Дефекты на внутренней поверхности кольцевого образца из стали 09Х16Н4Б-Ш после вылеживания в $25 \%$-ном растворе морской соли при комнатной температуре в течение 6 мес 12 дней 


\section{3. Результаты исследования}

\section{1. Магнитопорошковая дефектоскопия образцов из стали 09Х16Н4Б-Ш}

После проведения испытаний на коррозию под напряжением модельные образцы были подвергнуты магнитопорошковому контролю способом приложенного поля по ГОСТ 21105-87 «Контроль неразрушающий. Магнитопорошковый метод». Для намагничивания образцов применяли полюсное намагничивание с помощью намагничивающего устройства на высокоэнергоемких постоянных магнитах. Это устройство создает в межполюсном зазоре магнитное поле напряженностью более $150 \mathrm{~A} / \mathrm{cm}$. Измерения, проведенные с помощью магнитного структуроскопа КРМ-Ц показали, что коэрцитивная сила металла составляет примерно $40 \mathrm{~A} / \mathrm{cm}$. Для обеспечения максимального уровня чувствительности магнитопорошкового контроля материалов с такой коэрцитивной силой необходимо создание магнитного поля напряженностью не менее 45 А/см.

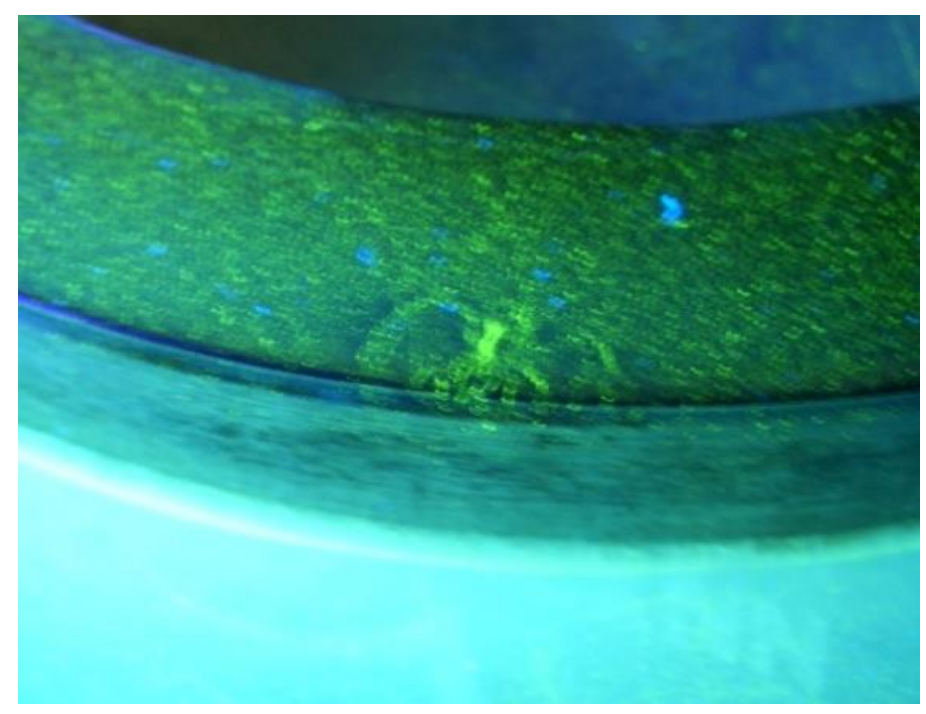

Рис. 6. Участок модельного образца с язвенной коррозией вблизи внешней цилиндрической поверхности после полива флюоресцентной магнитной суспензией. Облучение ультрафиолетовой лампой

Для магнитопорошковой дефектоскопии использовали флюоресцентную магнитную суспензию. После полива суспензией образцы освещали ультрафиолетовой лампой. Фотографии модельных образцов после полива флюоресцентной магнитной суспензией приведены на рис. 6 и 7. На рис. 6 представлена фотография участка модельного образца с язвенной коррозией вблизи внешней цилиндрической поверхности, на рис. 7 - фотография внутренней цилиндрической поверхности модельного образца с дефектами в виде поверхностных трещин. Следует отметить, что применение флюоресцентной магнитной суспензии позволяет получить более четкую дефектограмму, но при этом требуется источник ультрафиолетового излучения. 


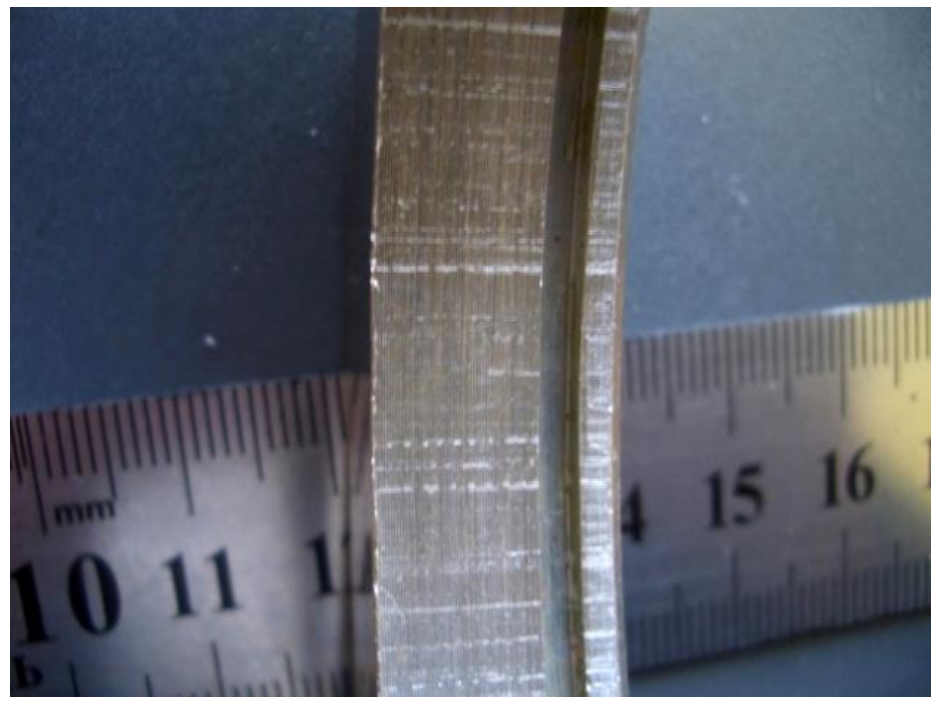

Рис. 7. Участок модельного образца с дефектами в виде поверхностных трещин после полива флюоресцентной магнитной суспензией. Облучение ультрафиолетовой лампой

Из приведенных данных следует, что магнитопорошковая дефектоскопия способом приложенного поля позволяет надежно выявлять дефекты в виде очагов язвенной коррозии и поверхностных трещин на образцах из стали 09Х16Н4Б-Ш.

\section{2. Феррозондовый неразрушающий контроль на примере стали 09Х16Н4Б-Ш}

Феррозондовый метод неразрушающего контроля (ГОСТ 21104-75) основан на выявлении феррозондовым преобразователем магнитного поля рассеяния дефекта в намагниченных изделиях и преобразовании его в электрический сигнал. Таким образом, феррозондовый метод отличается от магнитопорошкового лишь способом регистрации магнитных полей рассеяния в зоне дефекта. Для проверки эффективности феррозондового метода неразрушающего контроля обнаружения и локализации дефектов сплошности было использовано специальное устройство, позволяющее сканировать с постоянной скоростью феррозондовым преобразователем внутреннюю и наружную поверхности кольцевых модельных образцов. Сканирование проводили в наиболее нагруженной части образца, диаметрально расположенной по отношению к распорному клину. Намагничивание образца осуществляли так же, как и в случае магнитопорошковой дефектоскопии, с помощью намагничивающего устройства на высокоэнергоемких постоянных магнитах. В экспериментах использовали магнитометр с феррозондовым преобразователем Magnetoskop 1.069.

Полученные результаты представлены на рис. 8. Локальные неоднородности полей рассеяния, отмеченные на рис. 8 цифрами, идентифицируются с визуально видимыми выходами на внутреннюю поверхность образца трещинами 1 и 2 и полуцилиндрической канавкой 3. Наличие трещин подтверждается результатами магнитопорошкового контроля. Трещина, обозначенная на графике распределения тангенциальной составляющей вектора индукции цифрой 4, не попала в поле зрения объектива при фотосъемке, однако ее наличие тоже зафиксировано при визуальном осмотре, а также по результатам магнитопорошкового контроля.

Следует отметить, что сканирование феррозондовым преобразователем этого участка модельного образца с наружной стороны, более доступной для проведения измерений, тоже выявило наличие неоднородностей распределения магнитных полей рассеяния вблизи указанных выше дефектов. 

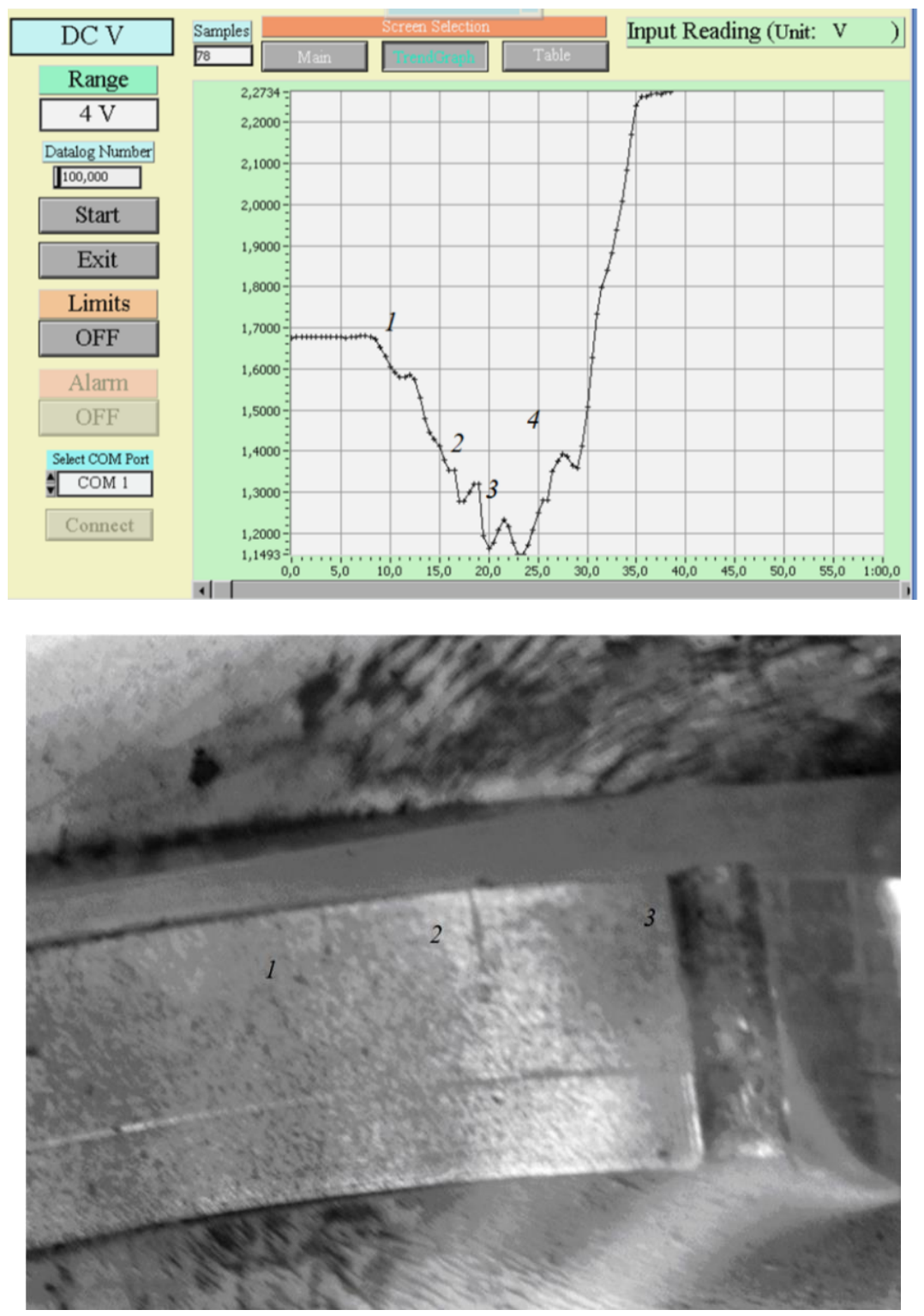

Рис. 8. Результаты измерения тангенциальной составляющей вектора магнитной индукции на поверхности образца после испытаний на коррозию под напряжением

\section{3. Вихретоковая дефектоскопия образцов из стали 09Х16Н4Б-Ш}

Был использован вихретоковый дефектоскоп «Вектор», предназначенный для контроля изделий основного производства и технологического оборудования в машиностроении, энергетике, металлургической промышленности, на железнодорожном, авиационном, автомобильном и трубопроводном видах транспорта, оснащенный дифференциальным вихретоковым преобразователемВТ-4.03.

Для настройки вихретокового дефектоскопа при контроле цилиндрических поверхностей кольцевых образцов из стали 09Х16Н4Б-Ш использовали бездефектные участки образцов, выявленные с помощью визуального, магнитопорошкового и феррозондового контроля. При установке преобразователя на бездефектный участок кольцевого образца амплитуда сигнала была равна $9 \mathrm{MB}$, фаза сигнала $-250^{\circ}$. Вблизи коррозионной язвы и трещин на внутренней стороне. 


\section{4. Заключение}

Модельные образцы в виде колец из высокопрочной коррозионностойкой стали 09Х16Н4Б-Ш подвергались испытаниям на коррозию под напряжением с целью получения искусственных дефектов в виде коррозионных язв и поверхностных трещин.

На указанных образцах была проверена эффективность магнитопорошкового, феррозондового и вихретокового методов контроля обнаружения дефектов сплошности в изделиях ответственного назначения из исследованной стали. Проведенные исследования показали, что магнитопорошковая дефектоскопия способом приложенного поля, феррозондовый и вихретоковый методы позволяют надежно выявлять дефекты в виде очагов язвенной коррозии и поверхностных трещин на изделиях из стали 09Х16Н4Б. Все три метода позволяют определять местоположение дефектов и оценивать их размеры. При этом вследствие высокой чувствительности, простоты реализации, сравнительно невысокой стоимости оборудования и расходных материалов, надежности выявления поверхностных дефектов в деталях любой формы, наглядности результатов испытаний магнитопорошковый метод является предпочтительным. Однако феррозондовый и вихретоковый методы требуют менее тщательной подготовки поверхности объекта к контролю и позволяют обнаруживать дефекты на большей глубине залегания.

\section{Благодарность}

При исследованиях использовано оборудование ЦКП «Пластометрия» ИМАШ УрО РАН.

Работа выполнена при поддержке Проекта № 18-11-1-11 «Разработка моделей деградации функциональных свойств материалов для ракетной техники при длительных сроках хранения и эксплуатащии» Комплексной программы УрО РАН: “Фундаментальнье исследования, ориентированные на высокотехнологические научно-производственные предприятия».

\section{Литература}

1. Горкунов Э. С. Магнитопорошковая дефектоскопия и магнитная структуроскопия. Методические рекомендации. - Екатеринбург : Изд. УрО РАН, 1999. - 140 с.

2. Шелихов Г. С. Магнитопорошковый метод - фактор повышения надежности сложных технических объектов // Контроль. Диагностика. - 2014. - № 3. - С. 24-29.

3. Намагничивающее устройство: пат. 33653 Рос. Федерация / Горкунов Э. С., Башков Ю. Ф., Дурницкий В. Н., Табачник В. П., ИМАШ УрО РАН. - № 2003116730/20 ; заявл. 05.06.2003 ; опубл. 27.10.2003. -2 с.

4. Бакунов А. С., Горкунов Э. С., Щербинин В.Е. Магнитный контроль. - М. : Изд. дом «Спектр», 2011. - 192 с.

5. On necessary measures for ensuring safe operation of pipeline transport using nondestructive testing methods / V. E. Shcherbinin, V. N. Kostin, Ya. G. Smorodinskii, A. P. Nichipuruk, A. B. Rinkevich, A. S. Shleenkov, B. V. Patramanskii, V. Loskutov // Russ. J. Nondestr. Test. 2011. - No. 12. - P. 842-851.

6. Reutov Yu. Ya., Shcherbinin V. E., Volkov A. V. Possibilities for the selection of magnetic field transducers for nondestructive testing // Russian Journal of Nondestructive Testing. - 2014. Vol. 50, iss 12. - P. 760-768. - DOI: 10.1134/S1061830914120080. 